Available online on 15.11.2017 at http://jddtonline.info
Journal of Drug Delivery and Therapeutics
Open Access to Pharmaceutical and Medical Research
$\begin{gathered}\text { opt-17, publisher and licensee JDDT, This is an Open Access article which permits unrestricted non- } \\ \text { commercial use, provided the original work is properly cited }\end{gathered}$

Open $\odot$ Access

Research Article

\title{
ANTIPROLIFERATIVE AND APOPTOGENIC EFFICACY OF ANTIDIABETIC DRUGS METFORMIN AND SITAGLIPTIN AGAINST MCF7 AND HEPG2 CANCER CELLS: A COMPARATIVE MOLECULAR STUDY
}

\author{
Mrinmoy Sarkar ${ }^{1}$, Sananda Dey ${ }^{1,2}$, Biplab Giri ${ }^{* 1,2}$ \\ ${ }^{1}$ Experimental Medicine \& Stem Cell Research Laboratory, Department of Physiology, West Bengal State University, Barasat, Kolkata 700 \\ 126, India \\ ${ }^{2}$ Department of Physiology, University of Gour Banga, Malda 732103, West Bengal, India
}

\begin{abstract}
Lifestyle and diet-related disorder type 2 diabetes (T2D), has reached epidemic margin globally. The relationships between diabetes and cancer are complex. However, evidence supports the hypothesis that obesity raises the risks of both T2D and certain cancers. A further complication arises from the controversy that drugs used in the treatment of T2D increase or decrease cancer risk or influence cancer diagnosis. Herein, we hypothesized that the antidiabetic medications can improve cancer outcome. In this study, we have studied the potency and efficacy of two well-known antidiabetic drugs metformin and sitagliptin. Although there are controversies for the usage of DDP4 inhibitors, we found that sitagliptin has a potent cytotoxic effect on both types of cancer cells (MCF7 and HepG2). It has also shown certain impact on early apoptogenic efficacy in HepG2 and late apoptogenic efficacy on MCF7 as well as the caspase-3 activity expression in both cell lines. In line of our study, it might be concluded that sitagliptin has significant antiproliferative and apoptogenic efficacy in MCF7 and HepG2 cancer cells, though it was observed to be lesser than that of metformin. Further thorough investigation in a cancer-diabetes animal model, as well as the trial on cancer-diabetic human subjects, is required to establish the efficacy of type 2 antidiabetic drugs in treating diabetic cancer patients.
\end{abstract}

Keywords: Metformin; Sitagliptin; DPP4 inhibitor; Cancer; Diabetes; Proliferation; Apoptosis;

Article Info: Received 27 Aug, 2017; Review Completed 17 Oct, 2017; Accepted 22 Oct, 2017; Available online 15 Nov, 2017

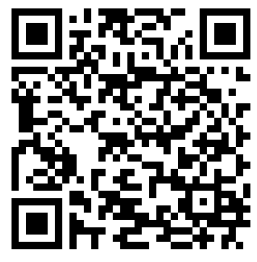

Cite this article as:

Sarkar M, Dey S, Giri B, Antiproliferative and apoptogenic efficacy of antidiabetic drugs metformin and sitagliptin against MCF7 and HEPG2 cancer cells: a comparative molecular study, Journal of Drug Delivery and Therapeutics. 2017; 7(6):11-21

DOI: http://dx.doi.org/10.22270/jddt.v7i6.1519

*Address for Correspondence

Biplab Giri, Department of Physiology, University of Gour Banga, Malda 732103, West Bengal, India. Email: bgiri.emscrl@gmail.com

\section{INTRODUCTION}

Drug designing and development are being attempted all over the world to meet every day's newer health complications, especially due to modern life style related diseases. Diabetes and cancer are the most dreaded diseases related to life styles of modern age. Apart from the cons of modern sedentary life style, we now a days, encounter a few more problems which lead to the serious outcomes due to several chronic and systemic diseases like - hormonal dysregulation, hyperglycaemia, metabolic syndrome and over all cancer. The present study relates the causes and their consequences with the contemporary interventions made by the scientific community. Most of the reasons, responsible for mentioned problems in human life style, are created by humans themselves. Behind the stated human diseases, excess use of chemicals and hormones do have a noteworthy presence. The result of this is accumulation of xenobiotic compounds in the human gut, liver and other tissues. This results in certain hormonal dysregulations in the body leading to various systemic diseases which in turn lead to certain mutations, sharing commonly contributory efficacy to result in carcinogenesis as well as diabetes. Apart from the ingestion of xenobiotic compounds and various other 
cancer-causing agents in any or the other form, the mutation can take place due to the high quantity of ultra violet rays in the environment.

Now, coming to the context of the present topic, we must say that using medications for what so ever reasons in an unsolicited manner is also largely responsible for various systemic disorders including the two diseases we are concerned about in this study. The unidentified side effects give reasons towards formation of various systemic and hormonal disorders. These disorders in turn give rise to diabetes and cancer.

Our focus would be to illustrate the reported links between the two of the most dreaded diseases in the light of previous studies on treating cancer by type- 2 antidiabetic drugs by other investigators and ours as well ${ }^{1,2}$. We shall look into the interventions made against cancer by some well documented anti-diabetic medicines. There are controversies of anticancer activity of certain antidiabetic drugs used in Type- 2 diabetic patient having cancer and some are beneficial ${ }^{2}$. The multifunctional role of these drugs is mainly due to their involvement in different molecular signaling pathways.

As stated earlier, that from previous reports from the scientific world, it was understood that diabetes and cancer are the most dreaded real-world health problems in the present decade. In course of developing newer drugs to combat cancer, several established drugs have been trialled against cancer. This took place in connection with the common symptoms shared by different life style related diseases. Often two diseases are resulted by a common dysregulation of cell signalling pathways. It is obvious then, that any substance that re-stabilizes the regulation of the aforesaid cellular signalling pathways, can definitely act against both the concerned diseases. On similar thoughts, investigators have been searching anti-cancer potentials in type- 2 anti-diabetic drugs since the two diseases do share a set of certain common cellular states.

Despite investigation into mechanisms linking Type-2 diabetes and cancer, there is a gap in knowledge about pharmacotherapy in cancer patients. Epidemiologic studies have shown that diabetic cancer patients on different anti-diabetic treatments have different survival. The clinically relevant question is, whether certain antidiabetic agents promote cancer while others inhibit cancer progression $^{1,2,} 3$. Although insulin and glucose promoted cancer cell proliferation and contributed to chemoresistance, metformin and rosiglitazone suppressed cancer cell growth and induced apoptosis ${ }^{3,4}$. Pioglitazone have been shown to induce apoptosis, as well as adipocyte differentiation ${ }^{2,5}$. Dipeptidyl dipeptidase-4 (DPP-4) inhibitor, a newly developed another group of drug used in diabetes ${ }^{6}$. DPP-4 is a multifunctional cell surface protein that is widely expressed in most cell types including $\mathrm{T}$ lymphocytes ${ }^{7}$. There is no expression of DPP-4 in normal healthy thyroid, while it is highly expressed in papillary thyroid carcinoma ${ }^{8}$. The use of DPP-4 inhibitor together with glucagon like peptide-2 (GLP-2) led to increased proliferation as well as elevated migratory activity. Therefore, the DPP-4 inhibitor could increase the risk of promoting an already existing intestinal tumor and may support the potential of colon cancer cell to metastasize. Again DPP-4 inhibits malignant phenotype of prostate cancer cells by blocking bFGF signaling pathway ${ }^{9}$.

In the present investigation, we will be providing information about the efficacy of two groups of Type-2 anti-diabetic drugs (Metformin \& Sitagliptin) in breast and liver cancer cells. In the present investigation we will compare the anticancer activity of these drugs at the level of different molecular signalling pathways.

\section{MATERIALS AND METHODS}

\section{Cell line procurement and Culture}

The cancer cell lines, MCF7 (Breast Cancer Cells) and HepG2 (Hepatocellular Carcinoma Cells) cells were kindly provided by Prof. Sanjay Ghosh, University of Calcutta. MCF-7 and HepG2 cells were maintained at $37^{\circ} \mathrm{C}$ in a $5 \% \mathrm{CO}_{2}$ atmosphere in IMDM (GIBCO, Life Technologies, NY, USA) and DMEM (GIBCO, Life Technologies, NY, USA) respectively, with $10 \%$ FBS (GIBCO, Life Technologies, NY, USA), substituted with 50 units $/ \mathrm{ml}$ penicillin and $50 \mathrm{mg} / \mathrm{ml}$ streptomycin (GIBCO, Life Technologies, NY, USA).

\section{Chemicals and Reagents}

Both of the drugs, sitagliptin and metformin, were purchased from SIGMA-ALDRICH (St. Louis, MO, USA). IMDM and DMEM culture media were purchased from GIBCO (Life Technologies, NY, USA), CellTiter-Blue $^{\circledR}$ for alamar blue assay was purchased from Promega corporation (Madison, WI, USA). RNeasy Mini Kit for RNA extraction and cDNA preparation kit were purchased from Qiagen, USA. The antibodies against PCNA, p21, p27, CDK4 and cyclin D were purchased from Abcam, USA, Cell Signalling Technologies, USA and Sigma (St. Louis, MO, USA). The anti-Rb secondary with HRP conjugate was also purchased from Sigma. The Caspase 3 Colorimetric Assay Kit was purchased from Sigma-Aldrich Inc. (St. Louis, MO, USA).

\section{Drug preparation for treatment}

Sitagliptin were dissolved in dimethylsulfoxide (DMSO; SIGMA, St. Louis, USA) to prepare a primary stock solution of $25 \mathrm{mM}$ and stored at $-20^{\circ} \mathrm{C}$. The final concentrations for treatments (i.e., $10 \mu \mathrm{M}$, and $100 \mu \mathrm{M}$ ) were subsequently prepared by diluting the primary stock with respective media for different cell lines. The concentration of DMSO used in this study did not affect cell survival and protein phosphorylation. Metformin is completely water soluble and was prepared using ultrapurified DNase, RNase, mutagen free water as stock solution and then subsequent relevant concentrations required for the tests.

\section{Alamar Blue assay}

The inhibition of proliferation was assessed using Alamar Blue assay (THE CELL TITER-BLUETM CELL VIABILITY ASSAY; Promega Corporation, Madison, USA). Cancer cell suspension was seeded to the wells of 96-well microtiter plates and treated with different concentrations of drugs. The plates were then incubated at standard cell culture conditions. $20 \mu \mathrm{L}$ of CelltiterBlue $^{\mathrm{TM}}$ reagent per $100 \mu \mathrm{L}$ of cell culture medium is 
then added in each well and incubated for another $3 \mathrm{~h}$. The organic substance Resazurin undergoes a blue shift to form Resorufin. Later, the colorimetric analysis was completed as per manufacturer's protocol and absorbance data were collected at $570 \mathrm{~nm}$ with a reference wave length of $600 \mathrm{~nm}$, which reveals the inhibitory potential of the drugs.

\section{Cytotoxicity test with normal human peripheral blood mononuclear cell (PBMNC)}

Cytotoxicity test with normal human peripheral blood mononuclear cells (PBMC) was also performed. After informed consent, $5 \mathrm{~mL}$ of blood drawn from one of the authors was heparinized $\left(10 \mathrm{U} \mathrm{mL}^{-1}\right)$ and mixed with an equivalent quantity of normal saline. The homogeneous blood was coated on $3 \mathrm{~mL}$ of histopaque and centrifuged for 15-20 min at $1500 \mathrm{rpm}$ at RT. PBMC were collected from the interface between histopaque and plasma, washed twice with normal saline and re-suspended in the culture medium. The cells were then maintained in standard culture conditions, in the presence or absence of the anti-diabetic drugs for $24 \mathrm{hrs}$. PBMC were stimulated with $2.5 \mathrm{mg} \mathrm{mL}^{-1}$ of phytohemoagglutinin and cytotoxicity was tested by alamar blue assay as described earlier ${ }^{10}$.

\section{Western blot analysis}

Cells were seeded for treatment onto $60 \mathrm{~mm}$ TC-treated plates (Nulgene, USA), washed with PBS at termination of treatment and lysed with RIPA lysis buffer (SigmaAldrich, USA) containing protease inhibitor cocktail (Sigma-Aldrich, USA). The whole cell lysate samples were then centrifuged at $10000 \mathrm{rpm}$ for 30 minutes at $4^{\circ} \mathrm{C}$ to collect the supernatant. Protein concentration is measured using Bradford reagent (Sigma-Aldrich, USA), and diluted 1:1 with SDS sample buffer (4\% SDS, $20 \%$ glycerol, $0.5 \mathrm{M}$ Tris- $\mathrm{HCl}(\mathrm{pH} 6.8$ ), 0.002\% bromophenol blue). $50 \mu \mathrm{g}$ of total protein, solubilised in SDS-sample buffer were resolved in each case in polyacrylamide (PAGE)-SDS gel system and electrotransblotted onto a PVDF membrane and blocked with 5\% reconstituted non-fat dried milk (Sagar Skimmed Milk Powder, Amul, India). Membranes were incubated and probed with the following antibodies: rabbit-antiPCNA (abcam, UK), rabbit-anti-p53, rabbit-anti-p21, rabbit-anti-p27, rabbit-anti-actin (all Cell Signaling Technologies, Leiden, The Netherlands) in a 1:1000 dilution or anti-cyclinD1 (Santa Cruz Biotechnology, UK). Primary antibodies were stained using HRPcoupled goat anti-rabbit or rabbit anti-mouse $\operatorname{IgG}$ and developed with ECL reagent (GE Healthcare Life Sciences, USA). Images were captured with the ImageQuant LAS 500 imaging system (GE Healthcare Life Sciences, USA).

\section{Flow-cytometric analysis of apoptosis}

The cells $\left(1 \times 10^{6}\right)$ were treated with metformin, pioglitazone and sitagliptin for $72 \mathrm{hrs}$. The cells were then washed with phosphate buffer saline and centrifuged at $1300 \mathrm{rpm}$ at $4^{\circ} \mathrm{C}$. The assay was then continued as per FITC Annexin V Apoptosis Detection Kit I (BD Pharmingen ${ }^{\mathrm{TM}}$; Material No. 556547) protocol. The cells were analyzed within 3-4 h by BD FACSVerse $^{\mathrm{TM}}$ flow cytometer (BD Biosciences, USA) with BD FACSuiteTM software. Flow cytometer was set for collecting data of 10,000 cells in each group. Flowcytometric reading will be taken using $488 \mathrm{~nm}$ excitation and band pass filters of 530/30 nm (for FITC detection) and 585/42 nm (for PI detection) ${ }^{2}$.

\section{Fluorescence microscopy}

MCF7 and HepG2 cells were analysed for apoptogenic activity by Hoechst [Hoechst 33342; Invitrogen, USA] staining following standard protocol ${ }^{11}$. The cells, treated or untreated, were added to a 24 well plate so that there remains a cell number of $1 \times 10^{4}$. After $72 \mathrm{~h}$ of treatment the cells were washed with PBS and Hoechst 33342, diluted in PBS, was added to the wells of culture plate. After 15-20 minutes of incubation the cells were washed again with PBS and adequate culture medium was added to cover the surface of the wells of the culture plate. The cells were then observed and photograph was taken using EVOS® FL Cell Imaging System (Life Technologies, USA).

\section{Caspase 3 analysis using assay kit}

$1 \times 10^{7}$ number of Cancer cells were collected after drug treatment along with same number of normal untreated cells. Cell lysates were prepared and using the lysates their caspase-3 activities were determined using Sigma Caspase 3 Assay Kit (Sigma-Aldrich, USA) using 96 Well Plate Microassay Method. Drug-treated and untreated cells were lysed according to the manufacturer's protocol and the lysate including the kit chemicals were incubated and the absorbance was read at $405 \mathrm{~nm}$ wavelength using iMark ${ }^{\mathrm{TM}}$ Microplate Absorbance Reader (Biorad, CA, USA).

\section{Statistical Analysis}

Data were analysed by Student's t-test or ANOVA wherever required. Experiments were conducted thrice and each test was performed in multiple well/numbers. Data has been represented as mean \pm SD wherever applicable and $p<0.05$ was considered significant.

\section{RESULTS}

\section{Determination of IC50 of the drugs in cancer cell lines and cytotoxicity test with normal human peripheral blood mononuclear cell (PBMNC) after 24 hours of treatment}

The IC50 of the anti-diabetic drugs were determined on the basis of 24 hours treatment by applying alamar blue assay (THE CELL TITER-BLUETM CELL VIABILITY ASSAY; Promega Corporation, Madison, USA). Table 1 is showing the determined IC50 values for the antidiabetic drugs.

Table 1: Determination of the IC50 of Metformin and Sitagliptin in MCF7 and HepG2 cells

\begin{tabular}{|l|l|l|}
\hline & IC50 in MCF7 & IC50 in HepG2 \\
\hline Metformin & $15.03 \mathrm{mM}$ & $21.18 \mathrm{mM}$ \\
\hline Sitagliptin & $1.65 \mu \mathrm{M}$ & $2.2 \mu \mathrm{M}$ \\
\hline
\end{tabular}

Expressed as mean value

After $24 \mathrm{~h}$ of treatment with each of the two drugs, the data stating the percentage of inhibition by the drugs 
shows that the drugs had affected the proliferative cancer cells much more than they inhibited the PBMNCs. Figure 1 describes the results thoroughly. The selective cytotoxicity of the anti-diabetic drugs to spare the normal cells suggests the usefulness of the drugs in exploiting their anti-cancerous properties in diabetic patients with breast and liver cancers.
A.
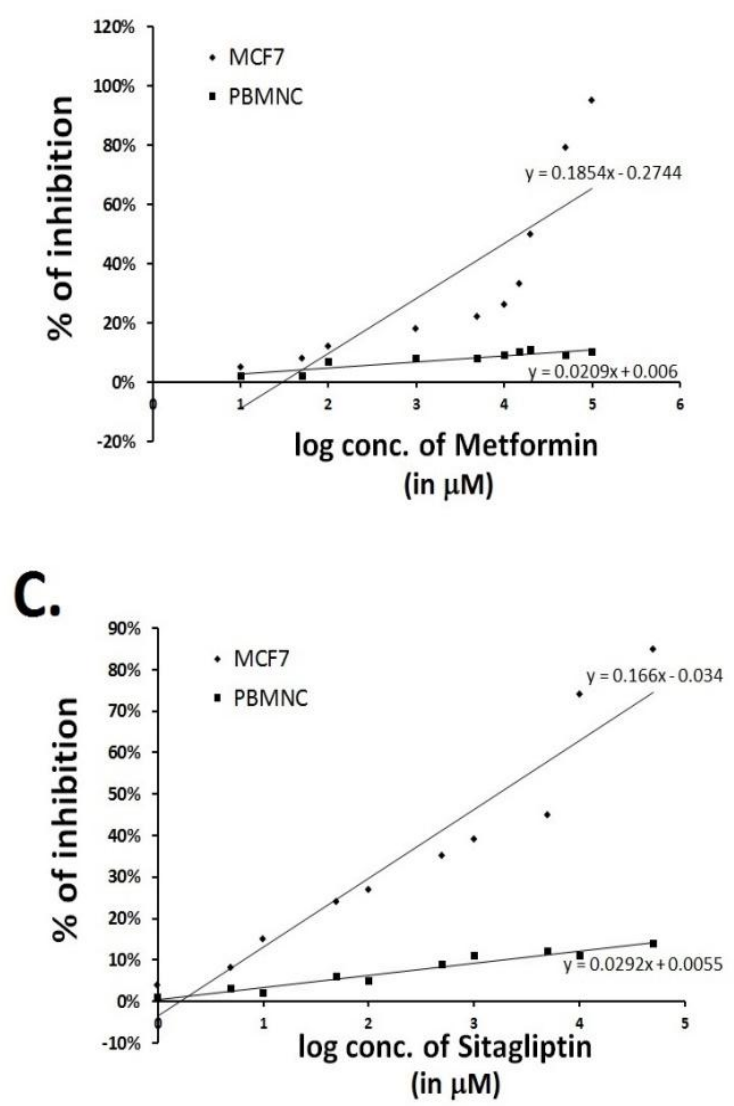

B.

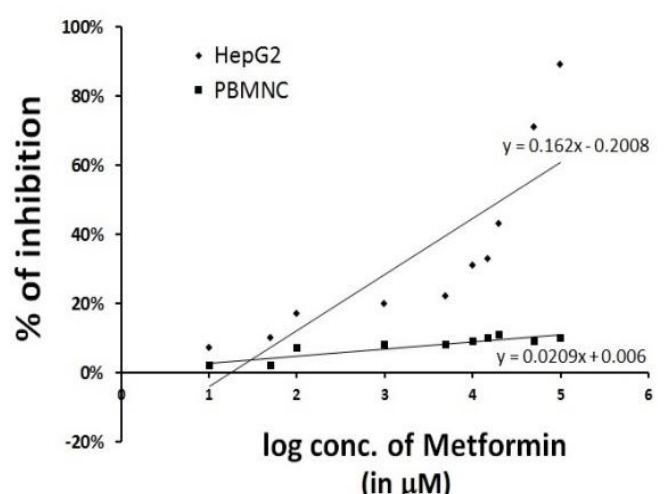

D.

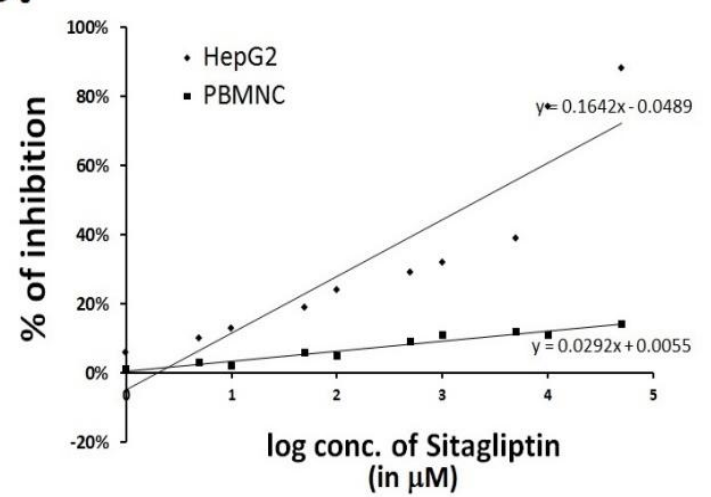

Figure 1: After $24 \mathrm{~h}$ of treatment with both the drugs, the data explains the percentage of inhibition by the drugs which show that the drugs had affected the proliferative cancer cells much more than they inhibited the PBMNCs. A and B showing the comparison of cytotoxicity of metformin to MCF7 and HepG2 respectively in comparison with PBMCs whereas, C and D shows the effect of sitagliptin.

\section{Cytotoxicity studies revealed metformin to be more effective as compared to sitagliptin}

According to our analysis, all the drugs have more or less cytotoxic or cell growth inhibitory properties in MCF7 breast cancer cells and HepG2 hepatocellular carcinoma cells. The cytotoxicity data obtained has been expressed through the cell viability curve in figure $2 \mathrm{~A}$ and $2 \mathrm{~B}$. Figure 2A explains the growth inhibitory properties of the anti-diabetic drugs on MCF7 breast cancer cells. From the apparent tendency of the curve it is clear, that the drugs pioglitazone and metformin have better effective cytotoxicity as compared with that of sitagliptin. The apparent tendency of cytotoxicity curve is almost similar in case of the other cell line we tested, the HepG2 (Figure 2B). But it seems the drugs are more efficient inhibitors of MCF7 cells.
Analytical information, obtained from the detailed data, suggests that in case of both the cell lines, significant decrease in the viability of the cancer cells was observed only after 48 hours of treatment. After 48 hours, the cytotoxicity by sitagliptin was similar to that of by the other two drugs, especially in HepG2 cell line. But it was not the same by its measure in following treatment hours, 72 hours and 96 hours. After 96 hours, where the viability after treatment with sitagliptin $10 \mu \mathrm{M}$ and 100 $\mu \mathrm{M}$ are $88.29 \%$ and $79.89 \%$ it deepens to $62.37 \%$ with $1 \mathrm{mM}$ metformin. In case of MCF7 cell line the cytotoxicity of sitagliptin is slightly enhanced; $87.82 \%$ and $78.92 \%$ with sitagliptin $10 \mu \mathrm{M}$ and $100 \mu \mathrm{M}$ respectively. The cell viability by metformin treatment has drastically fallen to $40.13 \%$ by metformin $1 \mathrm{mM}$. Figure 2C and figure 2D shows the growth of MCF7 and HepG2 cells respectively, in culture dishes under the phase contrast microscope. 
2A.

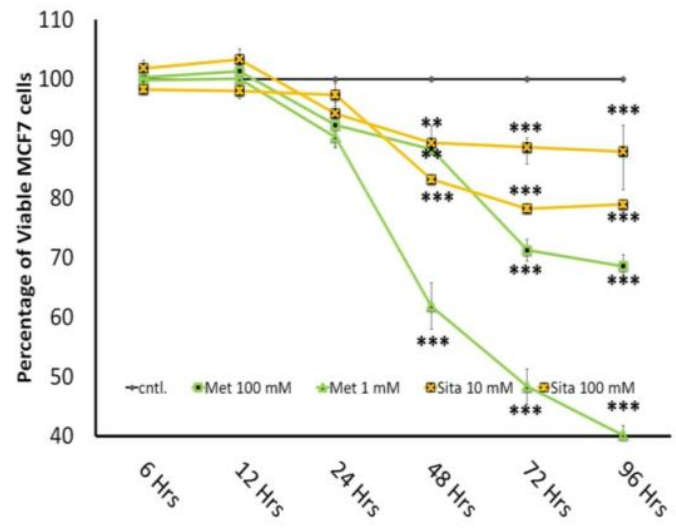

$2 B$.

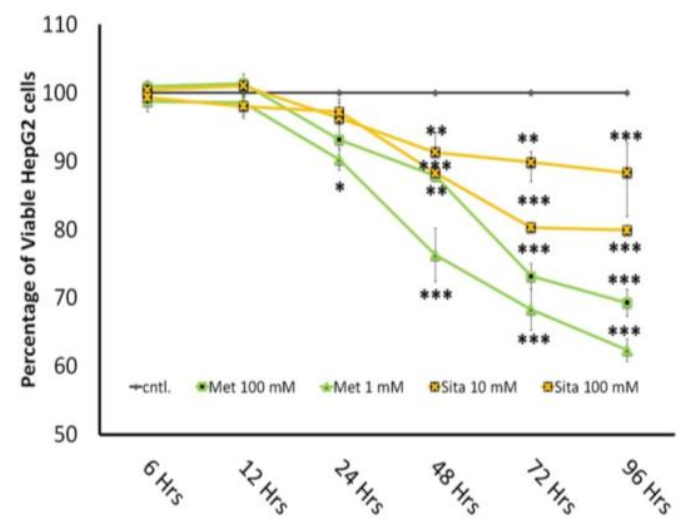

$2 C$.
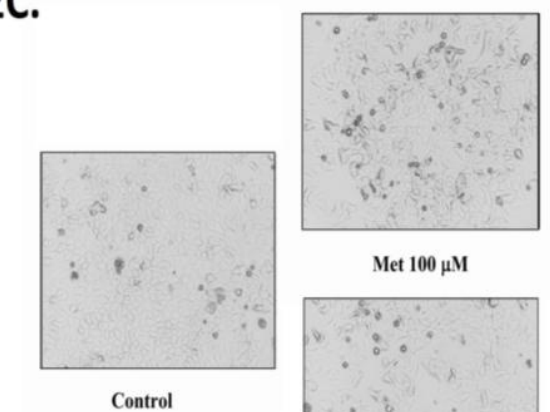

Met $100 \mu \mathrm{M}$

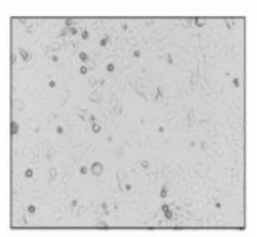

Sita $10 \mu \mathrm{M}$

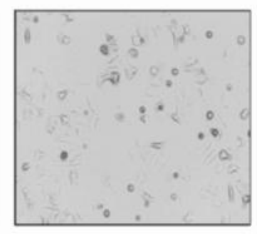

Met $1 \mathrm{mM}$

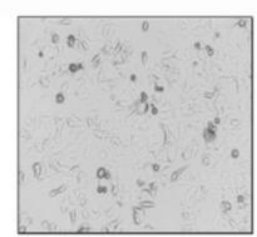

Sita $100 \mu \mathrm{M}$

2D.
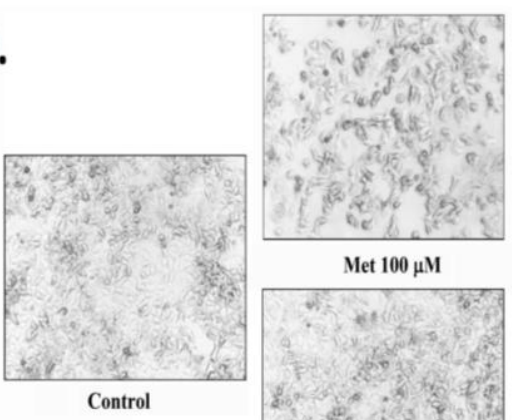

Met $100 \mu \mathrm{M}$

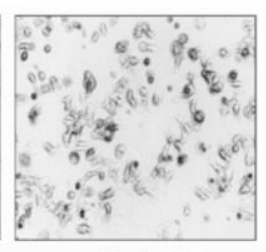

Met $1 \mathrm{mM}$

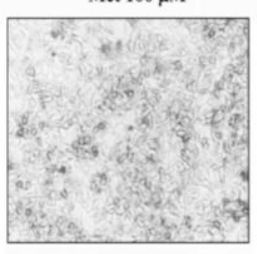

Sita $10 \mu \mathrm{M}$

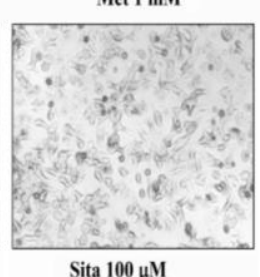

Figure 2: After determining the 24 hours' IC50 of the two drugs, the MCF7 and HepG2 cells were subjected to cell viability study on a time dependent manner. Alamar blue assay data were collected after 6, 12, 24, 48, 72 and 96 hours. Panel 2A (MCF7) and 2B (HepG2) clearly demonstrates the comparative effects of the two anti-

diabetic drugs in a time dependent manner. Panel 2C (MCF7) and 2D (HepG2) shows the phase contrast image of cell proliferation status after treating with drugs for 72 hours. For $2 \mathrm{~A}$ and $2 \mathrm{~B}$ values were taken as mean $\pm \mathrm{SD}(*=$ $p<0.05, * *=p<0.01$ and $* * *=p<0.001)$.

\section{Fluorescent staining of cancer cell nucleus showed the cytotoxic efficacy of anti-diabetic drugs on cancer cells}

The cytotoxicity of the anti-diabetic drugs on cancer cell lines was re-confirmed via fluorescent staining. The live cell nuclei were stained using Hoechst 33342 nuclear stain and the fluorescent image thus captured explained the previous data of decreasing cell viability by treating with anti-diabetic drugs. The data was collected after treating the cells for $72 \mathrm{~h}$ with or without drugs.

Figure 3.1 demonstrates the effects of the anti-diabetic drugs upon MCF7 breast cancer cells very clearly. Panel A denotes the control population of MCF7 cell, where the number of nuclei as well as the number of healthy nuclei is fairly high. Compared with that, panel B showed very minimal cell killing activity and resulted in a pool of a good number of healthy cells, whereas, panel $\mathrm{C}$ depicted a very small number of healthy nuclei and most of them showed disintegrated, broken-down and condensed chromatin resulting in fragmented nucleus. These are all signs that indicate the induction of cell death. Here, panel B and C demonstrated the treatment with metformin $100 \mu \mathrm{M}$ and $1 \mathrm{mM}$ respectively. Treatment with sitagliptin had its impact but the lower dose of it, i.e., $10 \mu \mathrm{M}$, could hardly change the anatomy of the cells or rather their nuclei (panel D) as compared with control cells. However, the $100 \mu \mathrm{M}$ treatment (panel E) showed some irregular chromatin staining that certainly suggests that sitagliptin $100 \mu \mathrm{M}$ dose has potential cytotoxic effects that induced cell death. Although, the affectivity is much lower than that of metformin $1 \mathrm{mM}$ dosage in MCF7 cells.

Figure 3.2 demonstrates the effects of the anti-diabetic drugs upon HepG2 hepatocellular carcinoma cells. Fluorescent staining of HepG2 cell line demonstrated a similar kind of story. Panel A denotes controluntreated HepG2 cells. Panel B and C shows the data of metformin $100 \mu \mathrm{M}$ and $1 \mathrm{mM}$ respectively. Panel D and $\mathrm{E}$ give away the result of sitagliptin treatment with $10 \mu \mathrm{M}$ and $100 \mu \mathrm{M}$ doses. Similar to the results obtained in case of MCF7 cells, in this case also treatment with metformin $1 \mathrm{mM}$ showed significant efficacy in inducing cell death (panel C) as compared with the $100 \mu \mathrm{M}$ dose (panel B). Unlike in the case of MCF7 cells, in HepG2 cells sitagliptin showed a very little growth inhibitory signs and effect to cause cytotoxicity in case of $10 \mu \mathrm{M}$ dose of the drug (panel D). However, the $100 \mu \mathrm{M}$ dose (panel E) had been observed to induce cell death to some extent. 

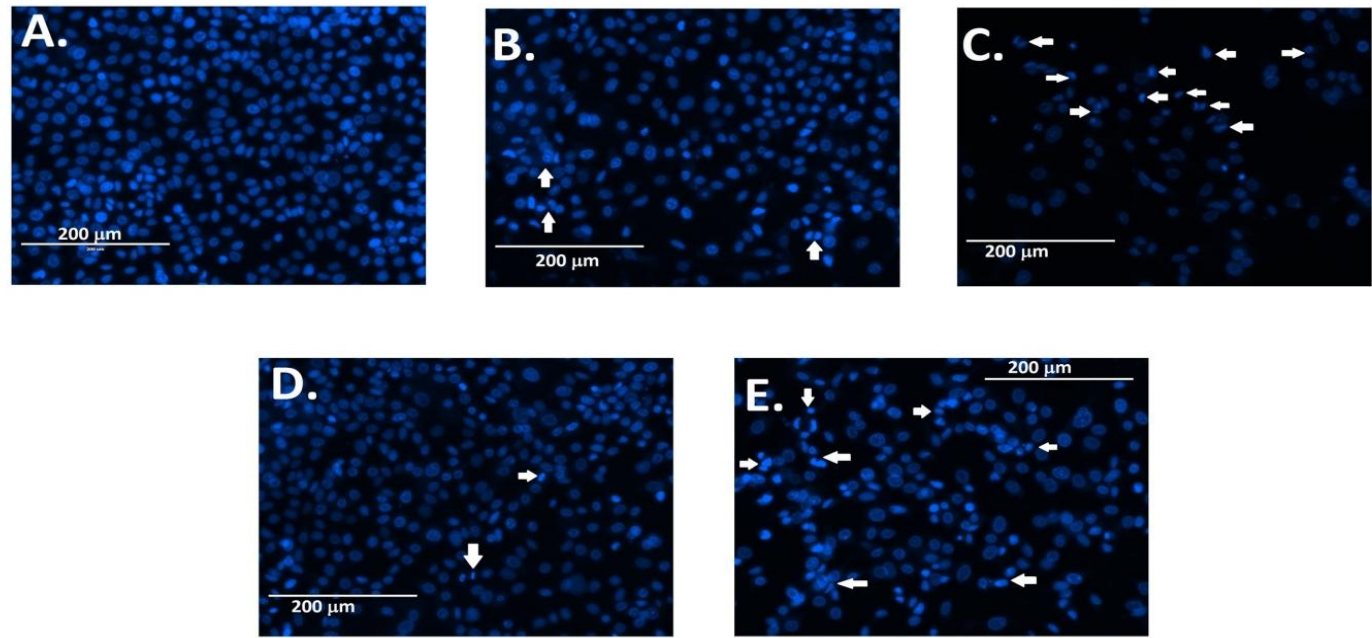

Figure 3.1
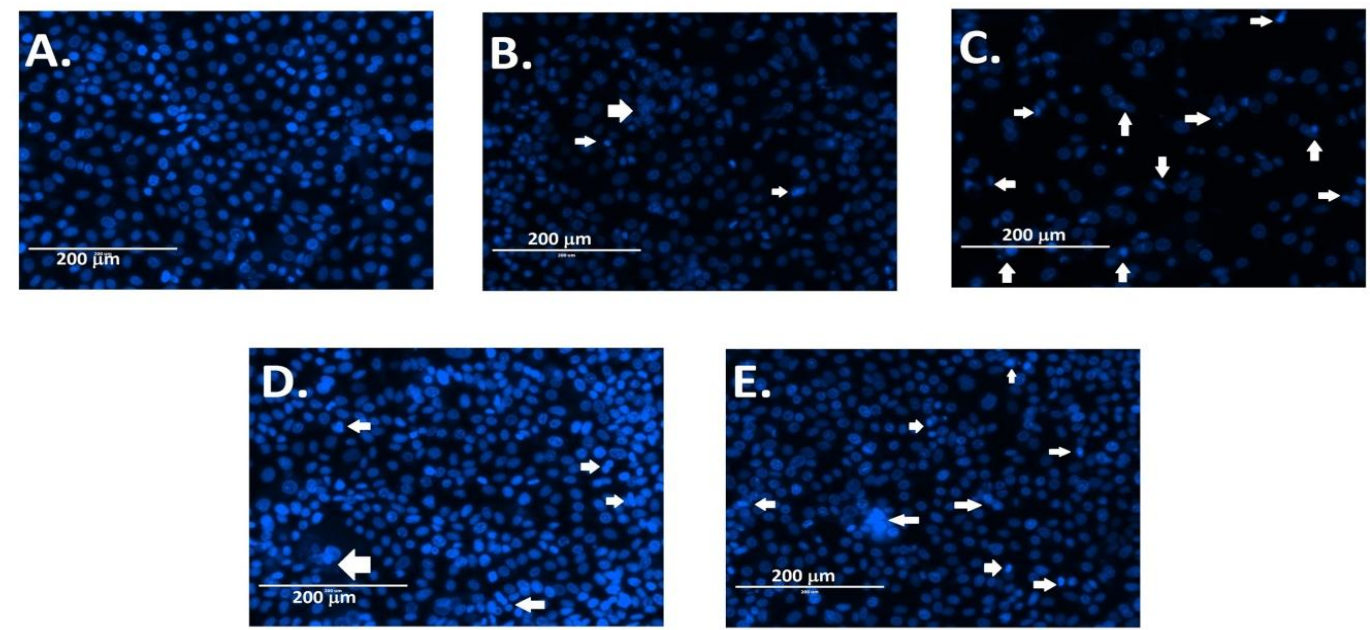

Figure 3.2

Figure 3: Fluorescent microscopic analysis after staining with Hoechst 33342 nuclear stain reveals the status of the nuclear fragmentation due to the treatment with sitagliptin and metformin. In this figure, metformin has been observed to be the more potent anti-cancer agent compared to sitagliptin especially in HepG2 cells (Figure 3.2). Nevertheless, sitagliptin also could induce the chromosomal disintegration and nuclear fragmentation as pointed by white arrow heads in the figure especially in MCF7 cells (Figure 3.1). [A=Control, B=Metformin $100 \mu \mathrm{M}, \mathrm{C}=$ Metformin $1 \mathrm{mM}, \mathrm{D}=$ Sitagliptin $10 \mu \mathrm{M}$, and E=Sitagliptin $100 \mu \mathrm{M}$.

AnnexinV-FITC/PI binding study explains the apoptogenic potentiality against cancer cells by the anti-diabetic drugs

In case of both drugs, two doses, including the one similar to the clinical dose, had been used to investigate the pro-apoptogenic potential of the anti-diabetic drugs.
After 72 hours of treatment, metformin $1 \mathrm{mM}$ and pioglitazone $10 \& 50 \mu \mathrm{M}$ significantly reduced the number of normal cells and increased with the similar proportion the early and late apoptotic cells. Table- 2 and table-3 shows the effect of metformin, sitagliptin and pioglitazone on MCF-7 and HepG2 cells.

Table 2: Effect of metformin and sitagliptin on flow cytometric AnnexinV-FITC/PI binding assay for MCF7 cell line at 72 hours

\begin{tabular}{|l|l|l|l|l|}
\hline & Normal Cells & Early Apoptotic Cells & Late Apoptotic Cells & Necrotic Cells \\
\hline Control & $74.94 \pm 2.92$ & $8.87 \pm 1.84$ & $14.78 \pm 2.29$ & $1.42 \pm 0.67$ \\
\hline Met 100 $\boldsymbol{\mu M}$ & $61.53 \pm 0.86$ & $8.09 \pm 0.62$ & $27.72 \pm 1.45 * * *$ & $2.66 \pm 0.91$ \\
\hline Met 1 mM & $34.01 \pm 0.75$ & $34.79 \pm 0.19 * * *$ & $28.96 \pm 0.71 * * *$ & $2.24 \pm 1.51$ \\
\hline Sita 10 $\boldsymbol{\mu M}$ & $62.28 \pm 1.33$ & $8.00 \pm 0.82$ & $25.99 \pm 0.63 * * *$ & $3.73 \pm 1.05$ \\
\hline Sita 100 $\boldsymbol{\mu M}$ & $61.8 \pm 0.63$ & $7.56 \pm 0.66$ & $27.18 \pm 1.63 * * *$ & $3.46 \pm 1.54$ \\
\hline
\end{tabular}


Table 3: Effect of metformin and sitagliptin and on flow cytometric AnnexinV-FITC/PI binding assay for HepG2 cell line at 72 hours

\begin{tabular}{|l|l|l|l|l|}
\hline & Normal Cells & Early Apoptotic Cells & Late Apoptotic Cells & Necrotic Cells \\
\hline Control & $99.83 \pm 0.09$ & $0.09 \pm 0.02$ & $0.02 \pm 0.02$ & $0.06 \pm 0.08$ \\
\hline Met $100 \mu M$ & $96.5 \pm 0.40$ & $2.97 \pm 0.08 * * *$ & $0.14 \pm 0.11^{* * *}$ & $0.40 \pm 0.29$ \\
\hline Met $1 \mathbf{~ m M}$ & $94.23 \pm 0.32$ & $5.28 \pm 0.44 * * *$ & $0.35 \pm 0.05 * * *$ & $0.15 \pm 0.11$ \\
\hline Sita $10 \mu M$ & $96.87 \pm 0.19$ & $2.6 \pm 0.13 * * *$ & $0.32 \pm 0.07 * * *$ & $0.21 \pm 0.13$ \\
\hline Sita $100 \mu M$ & $96.35 \pm 0.49$ & $2.52 \pm 0.37 * * *$ & $0.40 \pm 0.23 * * *$ & $0.73 \pm 0.21$ \\
\hline
\end{tabular}

In MCF7 cells (Table-2, Figure 4.1), after 72 hours of treatment, untreated normal cell pool was $74.94 \% \pm 2.92$ which significantly reduced to $61.53 \% \pm 0.86$ approximately when treated with $100 \mu \mathrm{M}$ metformin. The normal cell pool further got deducted to $34.01 \% \pm 0.75$ in the treatment group, treated with metformin $1 \mathrm{mM}$. In comparison, sitagliptin, though affected the normalcy of cells significantly, reduced the population of normal cells only up to $61.80 \% \pm 0.63$ with $100 \mu \mathrm{M}$ dose. As a result, there was a sharp increase in the total apoptotic cells' population, although, specifically, early apoptotic population could not be observed which may be due to early shifting of apoptotic phases of MCF7 cells in the experiments.
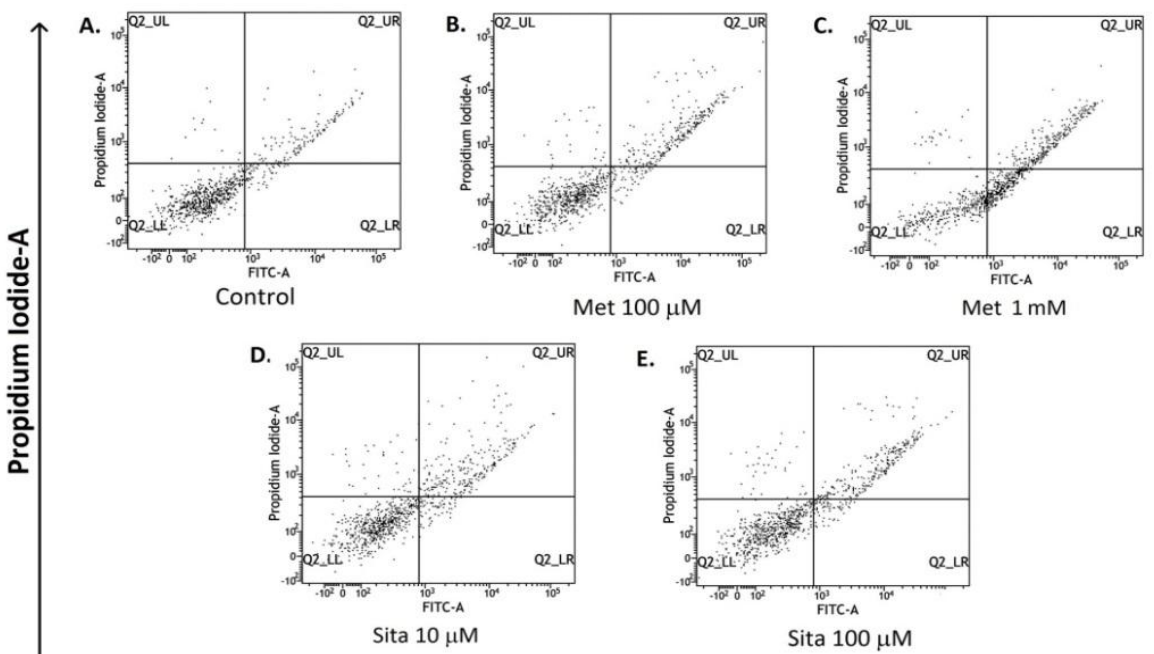

FITC-A

Figure 4.1

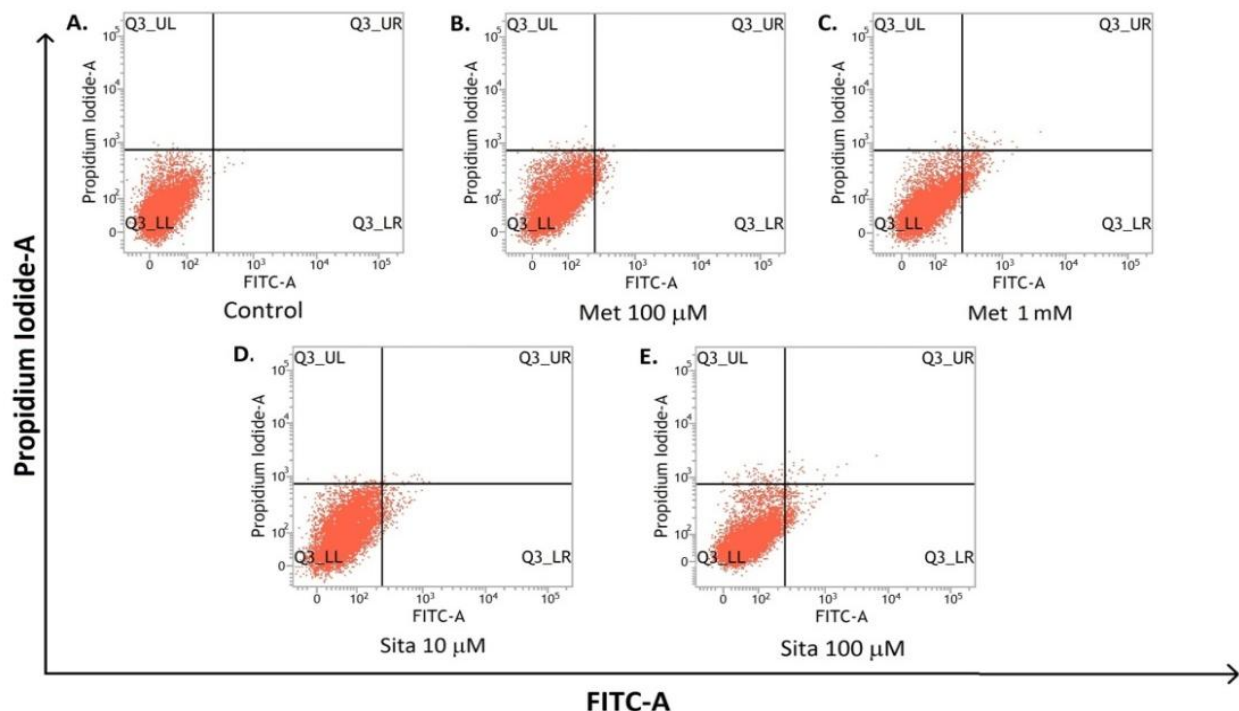

Figure 4.2

Figure 4: AnnexinV-FITC/PI binding assay by flow cytometer showed significant apoptogenic potential of sitagliptin and metformin. In case of MCF7 cells (Figure 4.1) sitagliptin could only increase the late apoptotic population significantly, but in HepG2 cells (Figure 4.2) sitagliptin induced both early and late apoptotic mechanisms. Table 2 and table 3 showed statistical data expressed as mean $\pm \mathrm{SD}(* * *=p<0.001)$ 
In HepG2 cells (Table-3, Figure 4.2), nearly similar scenario was observed with treated and untreated population. After 72 hours, the data was collected by flow cytometric analysis. Compared to the untreated control cells, the metformin $100 \mu \mathrm{M}$ and $1 \mathrm{mM}$ reduced cell pool in normal cell population and increased in early apoptotic cell populations significantly to $2.97 \% \pm 0.08$ and $5.28 \% \pm 0.44$ from $0.09 \% \pm 0.02$ in the untreated control group. Sitagliptin also induced apoptosis but not in a dose dependent manner as in the case of metformin, and increased the early apoptotic cell population to $2.6 \pm 0.13$ and $2.52 \pm 0.37$ by 10 $\mu \mathrm{M}$ and $100 \mu \mathrm{M}$ doses respectively. Eventually the similar sort of significant increase in the population of late apoptotic population was observed with all similar treatment groups.

\section{Protein expression data explains the anti-proliferative role of the drugs}

To investigate regarding the molecular mechanisms behind the anti-cancer potentials of the anti-diabetic drugs of our concern in this particular study, we targeted a few growthregulating molecules. We choose to study some basic protein expressions that could justify the role of the drugs in this context.

PCNA: The expression pattern of proliferating cell nuclear antigen (PCNA) -protein clearly suggests the drugs' antiproliferative role in cancer cells, especially metformin and pioglitazone. From figure 3 the difference of antiproliferative efficacy between the drugs can be understood clearly. Panel A demonstrates that in MCF7 cells, DNA replication was significantly reduced after 72 hours of treatment with metformin $1 \mathrm{mM}$. Compared with metformin, sitagliptin treatment reduced the expression of PCNA but only to a much lesser extent. Panel A', derived from immune blot of panel A showed the densitometric analysis of the protein expression.

Similar expression pattern was obtained from panel B which demonstrates the PCNA expression in HepG2 cell line. Sitagliptin $100 \mu \mathrm{M}$ treatment for 72 hours did reduce protein expression significantly as compared with untreated cells. Same as the MCF7 cell line, metformin $1 \mathrm{mM}$ treatment also, significantly reduced the expression of PCNA. Panel B' designates the densitometric analysis of panel B.

Cell cycle regulatory protein: Cell cycle regulatory proteins' expression were investigated and compared for both anti-diabetic drugs. p21 $1^{\text {Cip1 }}$ (alternatively p21 ${ }^{\text {Waf1 }}$ ), p2 $7^{\text {kip } 1}$ and CDK-4 were among the common proteins which were tested in both the cell lines (Figure 5).

Figure 5.1 Panels A', B', B", C', C", D', and E' describe the densitometric expression analysis of the cell cycle regulating proteins in $\mathrm{MCF} 7$ breast cancer cell line. It was evident from the immuno blot's densitometric data that $\mathrm{p} 21^{\text {Cip } 1 / \text { Waf1 }}$ protein expression was significantly increased after treating with the anti-diabetic drugs. Expressions of $\mathrm{p} 21^{\text {Cip1/Waf1 }}$ and $\mathrm{p} 27^{\mathrm{kip} 1}$ were observed to be significantly higher when treated with metformin as compared with untreated cells or sitagliptin treated cells as well. But treatment with sitagliptin certainly showed an anticancerous impact. CDK-4 and cyclin D protein expressions were also reduced significantly by metformin $1 \mathrm{mM}$ and sitagliptin $100 \mu \mathrm{M}$ in comparison with untreated cells.

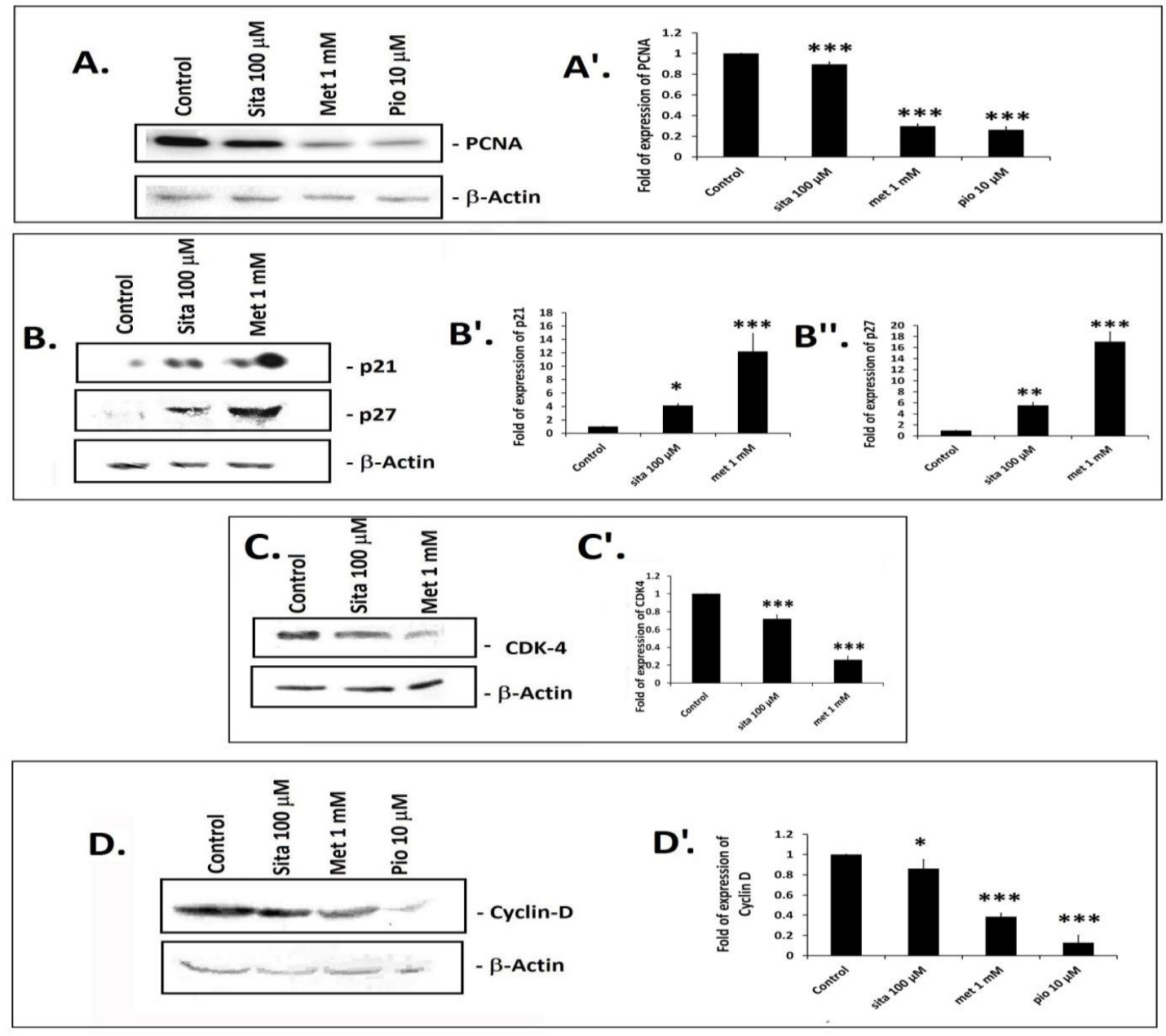

Figure 5.1 

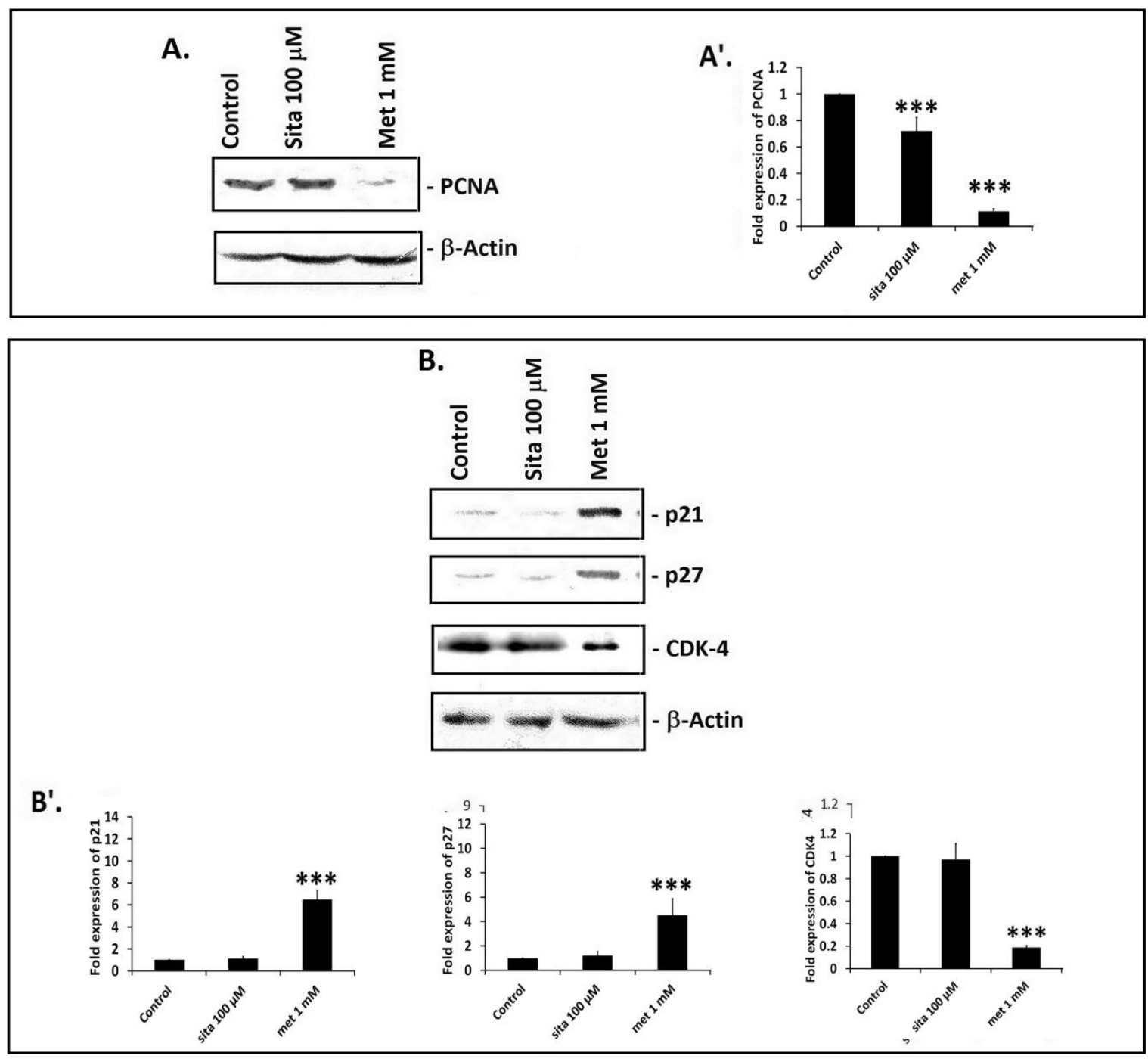

Figure 5.2

Figure 5: Western blotting analysis of proteins from the whole cell lysate after 72 hours of treatment, demonstrated the significant role of metformin and sitagliptin in inhibiting the cell growth in MCF7 breast cancer cells in vitro (Figure 5.1). Panel A shows the comparative activity of the drugs (sitagliptin, metformin and pioglitazone) in inhibiting the expression of PCNA of which densitometric analysis has been shown in panel $\mathrm{A}^{\prime}$. Likewise panels B, C and D shows comparative activity of drugs upon the expressions of CIP/KIP inhibitors (p21 and p27), CDK4 and Cyclin D1. Figure 5.2 demonstrated that sitagliptin could actually reduce the expression of PCNA significantly but it did not show significant impact upon the expression of p21/p27 or CDK-4 whereas metformin $1 \mathrm{mM}$ was significant in its activity to decrease the cell proliferative protein expressions in both MCF7 and HepG2 cells. Densitometric diagrams were prepared with mean \pm SD of densitometric data of the protein blots, repeated thrice. $(*=p<0.05$, ** $=p<0.01$ and $* * *=p<0.001)$.

Figure 5.2 shows the same protein expression in HepG2 cells. Expression pattern as obtained from HepG2 cells goes in line with that of MCF7 cells except that sitagliptin showed no significant impact in regulating the cell cycle proteins to show anti-cancer character. The cells treated with metformin showed significant increase in the expression of $\mathrm{p} 21^{\mathrm{Cip} 1 / \mathrm{Waf} 1}$ and $\mathrm{p} 27^{\mathrm{kip} 1}$, clearly understood from the densitometric analysis. The expression of CDK-4 significantly reduced after treating with metformin in contrast with sitagliptin. Panels $\mathrm{A}^{\prime}$ and $\mathrm{B}^{\prime}$ demonstrates the densitometric analysis of the blot.

\section{Caspase-3 study resolves the apoptogenic potential of the drugs}

To know if the drugs enhance the apoptotic mechanisms of the cancer cell lines (MCF7 and HepG2) the caspase3 expression study was performed using Sigma Caspase 3 Assay Kit (Sigma-Aldrich, USA). Figure 6 demonstrates the outcome of the assay.

Panel A clearly states that when MCF7 cells were treated with sitagliptin $(100 \mu \mathrm{M})$ and metformin (1 $\mathrm{mM}$ ), the cells were potentially induced to activate their caspase- 3 activity. From the Panel B, it was clear that sitagliptin and metformin also enhanced caspase-3 activity in HepG 2 cells. 
A.

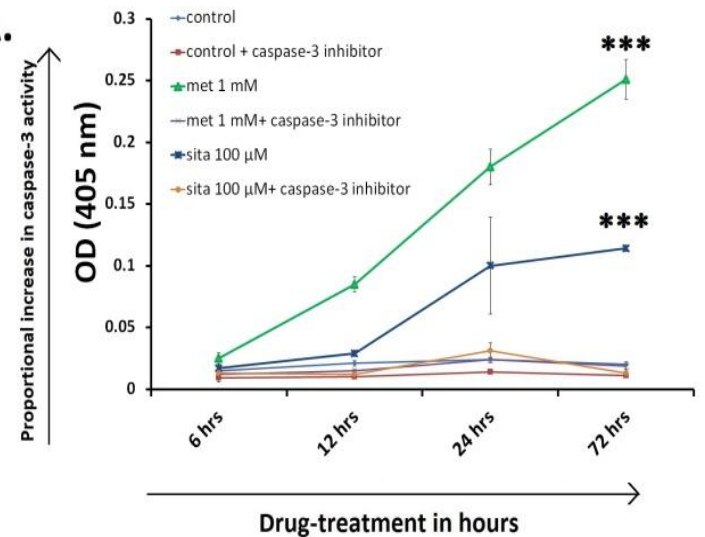

B.

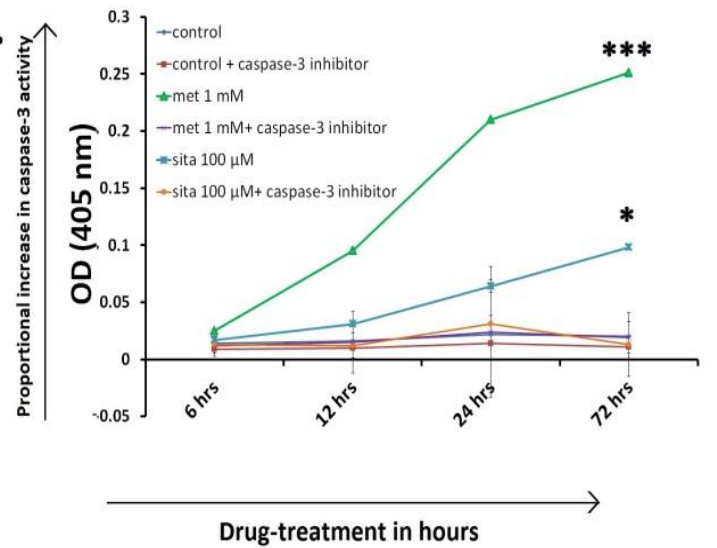

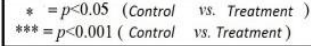

Figure 6: Caspase-3 activity study demonstrated that metformin and sitagliptin had significant impact upon the induction of caspase-3 to increase apoptogenic machinery in both the cell lines ( $\mathrm{A}=\mathrm{MCF} 7, \mathrm{~B}=\mathrm{HepG}$ ). The experiment was repeated four times and the values are given as mean $\pm \mathrm{SD}$. $(*=p<0.05$ and $* * *=p<0.001)$.

\section{DISCUSSION}

In current era, established drugs and other pharmacological substances, known to be useful against diseases, are being unveiled to use their unknown therapeutic potentials in various other pathophysiological conditions. Complexity and intracellular signalling meshwork and exclusive responsive behaviour of the pharmacological agents in any specific tissue are opening up newer uses other than their current use. In line with the same conception, herein, we are assessing the anti-cancer potencies of a useful type-2 anti-diabetic drug sitagliptin in comparison with another drug, metformin, a biguanide. Since investigators from different parts of the globe have demonstrated through pre-clinical in vivo and in vitro studies about increased pro-cancerous changes with the use of insulin or insulin secretagogues (sulfonylurea), the other anti-diabetics required a reconsideration regarding their use against cancer. In line with this, in our previous investigation it was shown that pioglitazone can reduce MCF7 cancer growth through sustained activation of MAPK in a PPAR $\gamma$ independent pathway. It has been put forward for the first time before the scientific community that in MCF7 cells pioglitazone can utilize the ERK1/2 phosphorylation as a tool to inhibit cancer growth ${ }^{2}$.

Several scientific interpretations have indicated about the hostile effects of using agonists of GLP-1 pathway ${ }^{12}$, 13, 14. The hazard of pancreatic cancer and pancreatitis is reported to be higher in individuals with diabetes and obesity than in the healthy people. The fact has been found that GLP-1 receptor (GLP-1R) activation inspires calcitonin secretion and countersigns the expansion of C-cell hyperplasia and medullary thyroid cancer (MTC) in rodents. Cases of depression have also been reported. Sitagliptin sometimes increases creatinine levels ${ }^{15}$. Pharmacological data suggest there might be an increased risk of cancer and muscular and neurological disorders. In contrast, we found out that sitagliptin, an agonist of GLP-1, could induce the p21 and p27 expression up to a certain extent in MCF7 cell line. This shows the sign of anti-cancer potentials of sitagliptin. Anti-proliferative character of the drug was also supported by the fact that treatment with the same could significantly decrease the expression of PCNA (proliferating cell nuclear antigen) in both cell lines. As stated earlier, sitagliptin had no supporting anti-cancer properties, rather it induced inflammation in certain tissues ${ }^{16}$ but our present data was in line with our recent review which illustrated various beneficial effects of the drug as well ${ }^{17}$.

Sliwinska A et al. (2015) in their report ${ }^{18}$ suggested that sitagliptin had no efficacy in inducing cell death in HepG2 cells. Abo-Haded HM et al. (2017) recently reported ${ }^{19}$ sitagliptin had a hepatoprotective effect against methotrexate induced liver toxicity. Wang et al. (2015) also explained in certain ischemic environment, sitagliptin inducing anti-apoptotic signaling. ${ }^{20}$. Tseng CH in 2017 stated that Sitagliptin may reduce prostate cancer risk in male patients with type 2 diabetes ${ }^{21}$. Tseng CH in 2017 stated that Sitagliptin may be able to reduce breast cancer risk in Women with type 2 diabetes ${ }^{22}$ but no evidence has been suggested regarding its efficacy in modulating the in vitro cell signaling thereby stopping cell proliferation. Whereas, we have found out an apoptogenic behaviour in sitagliptin when treated against MCF7 breast cancer cell lines and HepG2 liver cancer cell line. These observations have been reported for the first time in similar circumstances. In our study we demonstrated that though a lower than that of metformin but certain impact of sitagliptin on early apoptogenic efficacy in HepG2 and late apoptogenic efficacy on MCF7 as well as the caspase-3 activity expression in both cell lines.

DPP4 promoted EGF-induced epithelial cell transformation and mammary tumorigenesis via induction of PIN1 expression, suggesting that sitagliptin targeting of DPP4 could be a treatment strategy in patients with breast cancer ${ }^{23}$. In line with the previous finding, we showed for the first time that, Sitagliptin could induce an anti-cancer mechanism that in turn could significantly induce p21 and p27 expression in MCF7 breast cancer cell and suppressed PCNA 
expression although it showed insignificant changes of p21, p27 and CDK4 expression while considering HepG2 cells.

AnnexinV-FITC/PI binding assay by flow cytometer demonstrated that only metformin but not sitagliptin could induce early apoptotic cell death in breast cancer cells but it could vastly induce the late apoptotic signs in MCF7 cells whereas in liver cancer cell lines sitagliptin, like metformin and pioglitazone, was observed to induce cell death, both early and late apoptosis, significantly.

Metformin and Sitagliptin induced Capase3 activity dose dependently though sitagliptin did show a significantly lower effect than the other drugs. But to summarize the experiments, it should be emphasized that sitagliptin, unlike previous reports from various investigators ${ }^{2,18-22}$, has been observed to show cell-death inducing characters.

In conclusion, we found sitagliptin to show a potential cytotoxic effect on both type of cancer cells (MCF7 and HepG2). It has also showed certain impact on early apoptogenic efficacy in HepG2 and late apoptogenic efficacy on MCF7 as well as the caspase-3 activity expression in both cell lines. In the line of our study it might be concluded that sitagliptin has a potent anticancerous activity, though it was observed to be lesser than that of metformin, though further investigation is needed to establish its potentiality as a useful drug for the diabetic cancer condition patients.

\section{ACKNOWLEDGEMENT}

We want to acknowledge Prof. Sanjay Ghosh, University of Calcutta, for providing us the MCF7 and HepG2 cancer cell lines. We are thankful to Prof. Antony Gomes, University of Calcutta for his kind help in providing flow cytometer for the annexin binding analysis study. Authors are also thankful to SERB (Department of Science and Technology, Government of India) for funding the most part of the investigation through a research project fund (SR/FT/LS -132/2010) to Dr. Biplab Giri.

\section{CONFLICT OF INTEREST}

The authors have no conflict of interest.

\section{REFERENCES}

1. Giovannucci E, Harlan DM, Archer MC, Bergenstal RM, Gapstur SM, Habel LA, Pollak M, Regensteiner JG, Yee D, Diabetes and cancer: a consensus report, Diabetes Care, 2010; 33(7):1674-1685.

2. Kole L, Sarkar M, Deb A, Giri B, Pioglitazone, an antidiabetic drug requires sustained MAPK activation for its antitumor activity in MCF7 breast cancer cells, independent of PPAR- $\gamma$ pathway, Pharmacol Rep, 2016; 68(1):144-154.

3. Feng S, Cokus SJ, Zhang X, Chen PY, Bostick M, Goll MG, Hetzel J, Jain J, Strauss SH, Halpern ME, Ukomadu C, Sadler KC, Pradhan S, Pellegrini M, Jacobsen SE, Conservation and divergence of methylation patterning in plants and animals, Proc Natl Acad Sci U S A, 2010; 107(19):8689-94.

4. Kasznicki J, Sliwinska A, Drzewoski J. Metformin in cancer prevention and therapy, Annals of Translational Medicine, 2014, 2(6), 57.
5. Chang TH, Szabo E, Induction of differentiation and apoptosis by ligands of peroxisome proliferator-activated receptor gamma in non-small cell lung cancer, Cancer Res, 2000; 60(4):1129-1138.

6. Lambeir AM, Scharpé S, De Meester I, DPP4 inhibitors for diabetes--what next? Biochem Pharmacol, 2008; 76(12):1637-1643.

7. Havre PA, Abe M, Urasaki Y, Ohnuma K, Morimoto C, Dang NH, The role of CD26/dipeptidyl peptidase IV in cancer, Front Biosci, 2008; 13:1634-1645.

8. Ozóg J, Jarzab M, Pawlaczek A, Oczko-Wojciechowska M, Włoch J, Roskosz J, Gubała E, Expression of DPP4 gene in papillary thyroid carcinoma, Endokrynol Pol, 2006; 57(Suppl A):12-17

9. Wesley UV, McGroarty M, Homoyouni A, Dipeptidyl peptidase inhibits malignant phenotype of prostate cancer cells by blocking basic fibroblast growth factor signaling pathway, Cancer Res, 2005; 65(4):1325-1334.

10. Ghosh S, Mukhopadhyay S, Sarkar M, Mandal A, Das V, Kumar A, Giri B, Biological evaluation of a halogenated triterpenoid, $2 \alpha$-bromo-dihydrobelulonic acid as inhibitor of human topoisomerase II $\alpha$ and HeLa cell proliferation, Chem Biol Interact, 2017; 268:68-76.

11. Chazotte B. Labeling nuclear DNA with Hoechst 33342. Cold Spring Harb Protoc 2011.

12. Elashoff M, Matveyenko AV, Gier B, Elashoff R, Butler PC, Pancreatitis, pancreatic, and thyroid cancer with glucagonlike peptide-1-based therapies, Gastroenterology, 2011; 141(1):150-156.

13. Nelson M, Bhandari N, Wener J, Sitagliptin-induced pancreatitis - a longer road than expected, Clin Case Rep, 2014; 2(4):149-152.

14. Faillie JL, Yu OH, Yin H, Hillaire-Buys D, Barkun A, Azoulay L, Association of Bile Duct and Gallbladder Diseases With the Use of Incretin-Based Drugs in Patients With Type 2 Diabetes Mellitus, JAMA Intern Med, 2016; 176(10):1474-1481.

15. Hegedus L, Moses AC, Zdravkovic M, Le Thi T, Daniels GH, GLP-1 and calcitonin concentration in humans: lack of evidence of calcitonin release from sequential screening in over 5000 subjects with type 2 diabetes or nondiabetic obese subjects treated with the human GLP-1 analog, liraglutide, J Clin Endocrinol Metab, 2011; 96(3):853-860.

16. Tseng $\mathrm{CH}$. Sitagliptin use and thyroid cancer risk in patients with type 2 diabetes, Oncotarget, 2016; 7(17):24871-24879.

17. Sarkar M, Dey S, Giri B, Double Edge Effect of DPP4 Inhibitor Sitagliptin, A Type-2 Anti-Diabetic Drug, on Inflammation, Injury and Cancer, J Stem Cell Regen Biol, 2017; 3(1):1- 7 .

18. Sliwinska A, Rogalska A, Marczak A, Kasznicki J, Drzewoski J, Metformin, but not sitagliptin, enhances WP 631-induced apoptotic HepG2 cell death, Toxicol In Vitro, 2015; 29(5):1116-1123.

19. Abo-Haded HM, Elkablawy MA, Al-Johani Z, Al-Ahmadi O, El-Agamy DS, Hepatoprotective effect of sitagliptin against methotrexate induced liver toxicity, PLoS One, 2017; 12(3):1-16.

20. Wang XM, Yang YJ, Wu YJ, Zhang Q, Qian HY, Attenuating Hypoxia-Induced Apoptosis and Autophagy of Mesenchymal Stem Cells: the Potential of Sitagliptin in Stem Cell-Based Therapy, Cell Physiol Biochem, 2015; 37:19141926.

21. Tseng C-H, Sitagliptin may reduce prostate cancer risk in male patients with type 2 diabetes, Oncotarget, 2017; 8(12):19057-19064.

22. Tseng C-H, Sitagliptin May Reduce Breast Cancer Risk in Women with Type 2 Diabetes, Clin Breast Cancer, 2017; 17(3):211-218.

23. Choi HJ, Kim JY, Lim S, Kim G, Yun HJ, Choi HS, Dipeptidyl peptidase 4 promotes epithelial cell transformation and breast tumourigenesis via induction of PIN1 gene expression, British J Pharmacol, 2015; 172(21):5096-5109 